\title{
Development of A Low Angle Grain Boundary Resistant Single Crystal Superalloy YH61
}

\author{
H. Tamaki, A. Yoshinari, A. Okayama and S. Nakamura \\ Hitachi Research Lab., Hitachi, Ltd., 7-1-1 Ohmika, Hitachi, Ibaraki, 319-1292, Japan (E-Mail: hidekit@hrl.hitachi.co.jp) \\ K. Kageyama, K. Sato and T. Ohno \\ Metallurgical Research Lab., Hitachi Metals, Ltd., 2107 Yasugi, Yasugi, Shimane, 692-8601, Japan
}

\begin{abstract}
In this paper, a new single crystal (SC) superalloy YH61 is proposed to solve the problem of grain defects which are present in single crystal buckets or vanes of industrial gas turbines. First, the effects of solution heat treatment on various properties of the SC with and without grain defects were evaluated. Increasing the solution-heat-treated area was found to have a positive effect on the strength of a defect-free SC but harmful for the strength of a grain boundary and growth of recrystallization. The solution heat treatment condition for YH61 was determined after considering properties of both the defect-free SC and the SC with grain defects. Secondly, the effects of grain boundary misorientation angle $(\alpha)$ on the mechanical properties of grain boundaries were examined at several temperatures. No significant decrease in strength was found with increasing $\alpha$ at temperatures below about $800^{\circ} \mathrm{C}$, although the fall-off of strength was observed with increasing $\alpha$ at temperatures above about this temperature. Even when a significant decrease in strength was not observed, unexpected deformation behavior was found with increasing $\alpha$ because the Schmid factor for the slip system was also increased with increasing $\alpha$. In a strain-controlled LCF test, another type of deformation was observed for higher $\alpha$ values. This deformation caused significant fall-off of life as a function of $\alpha$. From the results of long term creep-rupture tests, YH61 was found to show similar creep-rupture strength to a second generation single crystal superalloy under certain conditions although YH61 contains higher levels of grain boundary strengthening elements.
\end{abstract}

Introduction

Application of single crystal (SC) buckets and vanes in aero-engines has significantly improved the engine performance. In the field of industrial gas turbines (IGT), application of SC components is necessary for improving the efficiency of IGT due to increases in gas-firing temperature. Although this demand is common to all IGT manufacturers, directionally solidified (DS) buckets and vanes are still the mainstream technology for IGT especially in the case of heavy-duty machines. Although there have been considerable efforts for adopting SC components for IGTs ${ }^{[1][2]}$, only two IGT manufacturers have announced that they have introduced SC buckets or vanes into their machinery ${ }^{[3][4]}$.

The main reason why SC components have not been widely adopted for IGT is the casting problems of the SC for IGT. Grain defects such as low angle grain boundaries (LAB), high angle grain boundaries (HAB) and recrystallization tend to occur in IGT buckets or vanes, since their sizes are larger and their shapes are more complicated than those of the aero-engines' components. Because of these reasons, the casting yield of the SC for IGT is significantly lower and their cost is higher than the DS components.

If the resistance of SC superalloys to $\mathrm{LAB}$ or $\mathrm{HAB}$ is increased, higher yields and lower costs can be realized for SC buckets and vanes in IGT. In order to meet these demands, a new SC superalloy, YH61 (Table 1) ${ }^{[5]}$ has been developed. Under certain conditions, creep-rupture strength of the defect-free YH61 is similar to that of a second-generation SC superalloy ${ }^{[6]}$, although YH61 contains higher amounts of boron, carbon and hafnium and requires only a partial solution heat treatment (Figure 1). 
Table 1 Nominal Composition of YH61, mass\%.

\begin{tabular}{llllllllllll} 
Cr & Co & W & $\operatorname{Re}$ & Mo & Ta & Nb & Al & Hf & C & B & Ni \\
\hline
\end{tabular}

$\begin{array}{lllllllllll}7.2 & 1.0 & 8.8 & 1.4 & 0.9 & 8.8 & 0.8 & 5.0 & 0.25 & 0.07 & 0.02 \\ \text { Balance }\end{array}$

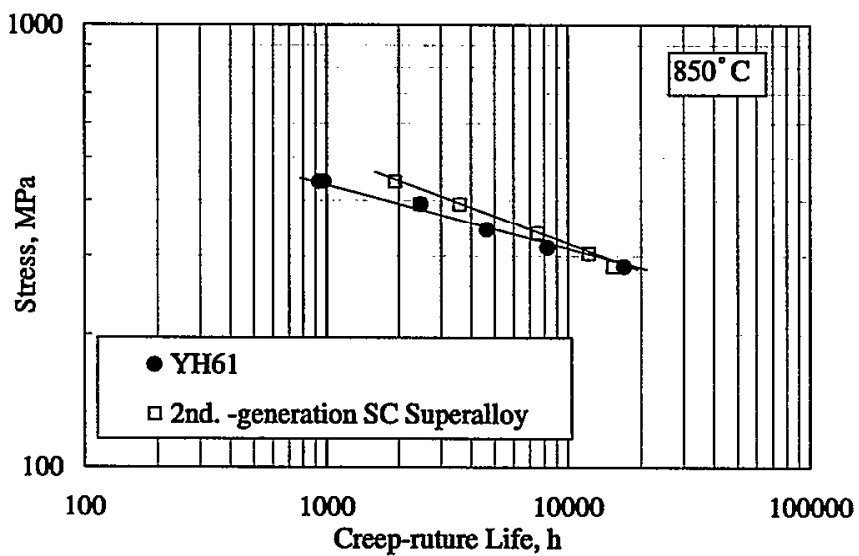

Figure 1: Stress-rupture curves for YH61 and a second-generation SC superalloy ${ }^{[6]}$ at $850^{\circ} \mathrm{C}$. Creep-rupture strength of YH61 is similar to that of the second-generation superalloy when creep-rupture life is longer than $10000 \mathrm{~h}$.

In order to utilize YH61 in IGT, the following targets should be achieved:

(1) A proper solution heat treatment condition which is compatible with both defect-free SC strength and LAB or HAB strength,

(2) The degree of $\alpha$ which can satisfy the design requirement for each part should be maximized.

It is generally accepted that higher creep-rupture strengths along the solidification direction of SC and DS can be achieved by increasing the volume percent of fine $\gamma^{\prime[7]}$. Higher solution heat treatment temperatures are also known to increase the volume percent of fine $\gamma^{\prime}$. For these reasons, solution heat treatment temperatures close to the incipient melting points have been adopted for conventional SC superalloys. Because such higher solution heat treatment temperatures can be achieved by removing grain boundary strengthening elements such as boron, hafnium and zirconium from the alloys, the conventional SC alloys contain a limited range of LAB. Ross and O'Hara ${ }^{[8]}$ have reported a unique SC superalloy that has moderate LAB strength but higher grain boundary strength than this alloy required for IGT.

For alloys with grain boundary strengthening elements, Cetel and Duhl pointed out that the creep-ductility for DS in the transverse direction is decreased with increasing volume percent of fine $\gamma^{\prime}{ }^{[9]}$. This increase was also found to decrease the creep-rupture life of DS in the transverse direction even in an alloy which contains grain boundary strengthening elements ${ }^{[5]}$. Especially, a higher volume percent causes a significant decrease in the creep-rupture life of DS in the transverse direction. Thus, for achieving higher strength of $L A B$ and $H A B$, both the addition of the grain boundary strengthening elements and optimizing solution heat treatment conditions seem to be necessary. This paper discusses optimization of the solution heat treatment condition for SC superalloys with grain defects.

Ross and O'Hara ${ }^{[8]}$ and Burkholder et al. ${ }^{[10]}$ studied the relationship between grain boundary misorientation angle $(\alpha)$ and $\mathrm{LAB}$ or HAB strength. Although they discussed the fall-off (or retention) of creep-rupture life as a function of $\alpha$, the change of deformation mechanism with increasing $\alpha$ should also be considered. If one grain is rotated towards another in order to increase $\alpha$, the Schmid factor for the rotated grain changes. When investigating the effect of $\alpha$ on the strength of $L A B$ or HAB bearing $S C$, both the effect of $\alpha$ on grain boundary strength and on the rotated grain strength should be considered since the strength of the rotated grain is also affected by the changed Schmid factor. This paper discusses this effect of $\alpha$ on the strength of LAB or $\mathrm{HAB}$ bearing $\mathrm{SC}$ at various temperatures and stresses by considering the above mentioned issues.

\section{Experimental Procedure}

\section{Effect of Solution Heat Treatment Conditions}

Seven $150 \mathrm{~kg}$ - master alloys and one $1.5 \mathrm{ton}$ - master alloy of YH61 were prepared for this study. SC bars $(\phi 15 \times 165 \mathrm{~mm})$ and DS slabs $(100 \times 15 \times 250 \mathrm{~mm})$ were cast from the master alloys by a mold withdrawal method.

The conditions of the multistep solution heat treatment adopted for this alloy are listed in Table 2.

Table 2 Solution Heat Treatment Conditions

\begin{tabular}{|c|c|}
\hline Condition No. & Condition for Final Step \\
\hline A & $1250^{\circ} \mathrm{C} / 4 \mathrm{~h} / \mathrm{AC}$ \\
\hline B & $1260^{\circ} \mathrm{C} / 4 \mathrm{~h} / \mathrm{AC}$ \\
\hline C & $1270^{\circ} \mathrm{C} / 4 \mathrm{~h} / \mathrm{AC}$ \\
\hline D1 & $1280^{\circ} \mathrm{C} / 1 \mathrm{~h} / \mathrm{AC}$ \\
\hline D & $1280^{\circ} \mathrm{C} / 4 \mathrm{~h} / \mathrm{AC}$ \\
\hline D8 & $1280^{\circ} \mathrm{C} / 8 \mathrm{~h} / \mathrm{AC}$ \\
\hline D20 & $1280^{\circ} \mathrm{C} / 20 \mathrm{~h} / \mathrm{AC}$ \\
\hline E & $1290^{\circ} \mathrm{C} / 4 \mathrm{~h} / \mathrm{AC}$ \\
\hline
\end{tabular}

The aging condition for all specimens was $1080^{\circ} \mathrm{C} / 4 \mathrm{~h} / \mathrm{AC}$ followed by $871^{\circ} \mathrm{C} / 20 \mathrm{~h} / \mathrm{AC}$.

Specimens for evaluating the perfect SC's mechanical properties were machined from $\mathrm{SC}$ bars. The stress axis of the specimens was parallel to the growth direction of SC bars and was within $10^{\circ}$ from the $\langle 100\rangle$ direction. Specimens machined from DS slabs were used for evaluating mechanical properties of the SC with grain defects such as HAB. The stress axis of the specimens was the DS transverse direction which was perpendicular to grain boundaries. 
A schematic of the specimen used for evaluating the effect of solution heat treatment conditions on the growth of recrystallized grain is illustrated in Figure 2. In this study, an alloy SC610 [11] (Ni $-7.5 \mathrm{Cr}-7.2 \mathrm{~W}-1.4 \mathrm{Re}-0.8 \mathrm{Mo}-8.8 \mathrm{Ta}-1.7 \mathrm{Nb}-5.0 \mathrm{Al}-0.1 \mathrm{Hf}$ $-1.0 \mathrm{Co}$, mass \%) was adopted for the evaluation for the following reasons: (a) a carbon free alloy was selected to evaluate the obstacle effect of only the non-solutioned $\gamma^{\prime}$ on the growth of recrystallized grains, (b) additionally, the $\gamma^{\prime}$ solvus temperature of the selected alloy should be similar to YH61. Specimens were cut perpendicular to the growth direction from as-cast SC bars. Deviation of the $\langle 100\rangle$ direction from the growth direction was within $10^{\circ}$. The wire-cutting method was utilized in order to have low residual stresses. One side of the cut surface was polished by \#1200 grade polishing paper followed by $0.06 \mu \mathrm{m} \mathrm{Al}_{2} \mathrm{O}_{3}$ slurry polishing. A nucleus for recrystallization was made by loading the sample in a Brinell hardness tester. A load of $9800 \mathrm{~N}$ was applied on the polished surface for 30 second, and then the specimens were solution-heat-treated. After the solution heat treatment, the maximum depth of the recrystallized grain was evaluated.

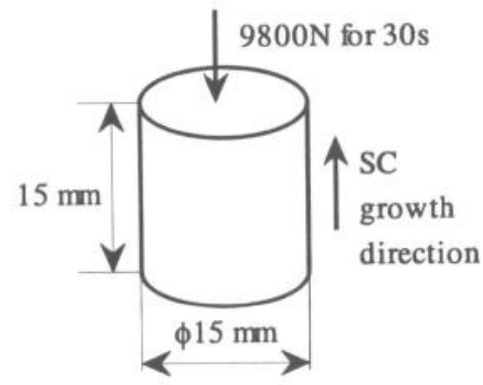

Figure 2: Schematic of the specimen for evaluating the effect of solution heat treatment on the growth of recrystallization.

\section{The Effect of Grain Boundary misorientation angle}

Bi-crystalline slabs described in Figure 3 were cast from the same master alloys mentioned above. The growth direction of both seeds was $<001>$, which corresponded to the longitudinal direction of the slab. The primary seed was set in order to align the $\langle 110\rangle$ direction parallel to the transverse direction of the slab. The $<110\rangle$ direction of the second seed was rotated from transverse direction by $\alpha$. Consequently, a grain boundary with a misorientation angle $\alpha$ was present along the center of the slab. Specimens were machined from the slabs parallel to the transverse direction. The grain boundary lay perpendicular to the stress axis in the middle of the specimen. The stress axis of the primary grain was parallel to the $\langle 110\rangle$ direction, and the stress axis of the second grain deviated from the $\langle 110\rangle$ direction by $\alpha$ in $\{100\}$ plane. The maximum value of $\alpha$ was $20^{\circ}$ in this study. Specimens were later solution-heat-treated according to the condition D listed in Table 2 followed by aging for which conditions were given above.

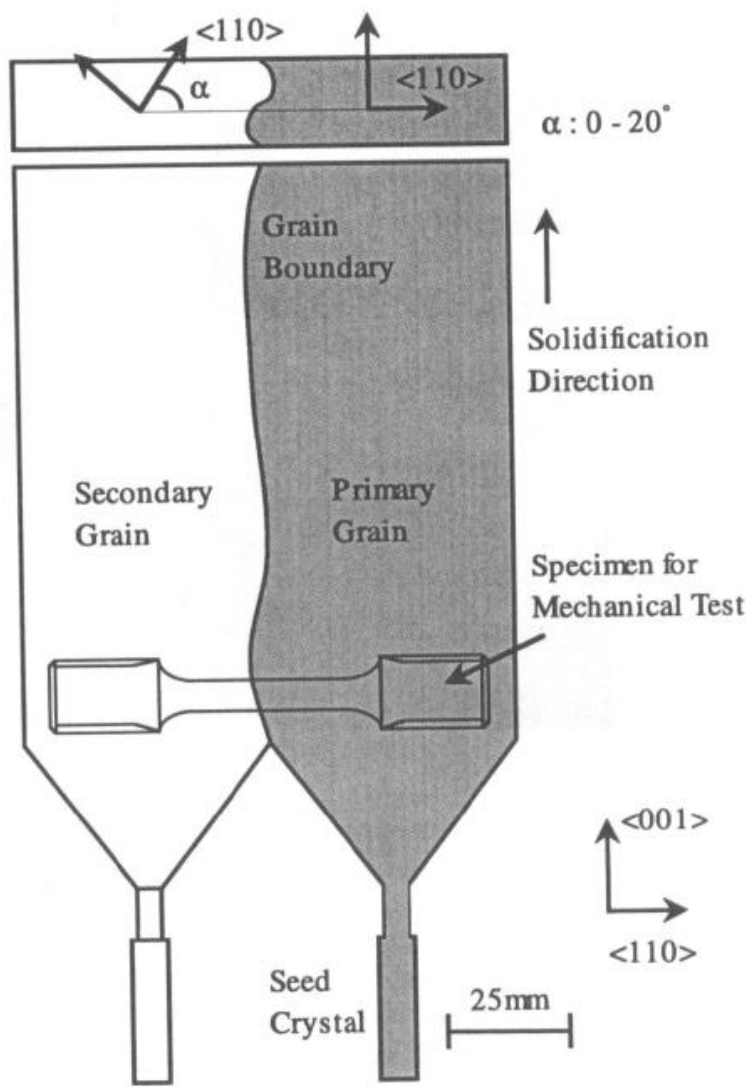

Figure 3: Schematic of the bi-crystalline slab for evaluating effect of $\alpha$ on strength of SC with LAB or HAB. Misorientation angle $(\alpha)$ was defined as rotation angle of the secondary grain against the primary grain on the $\{100\}$ plain.

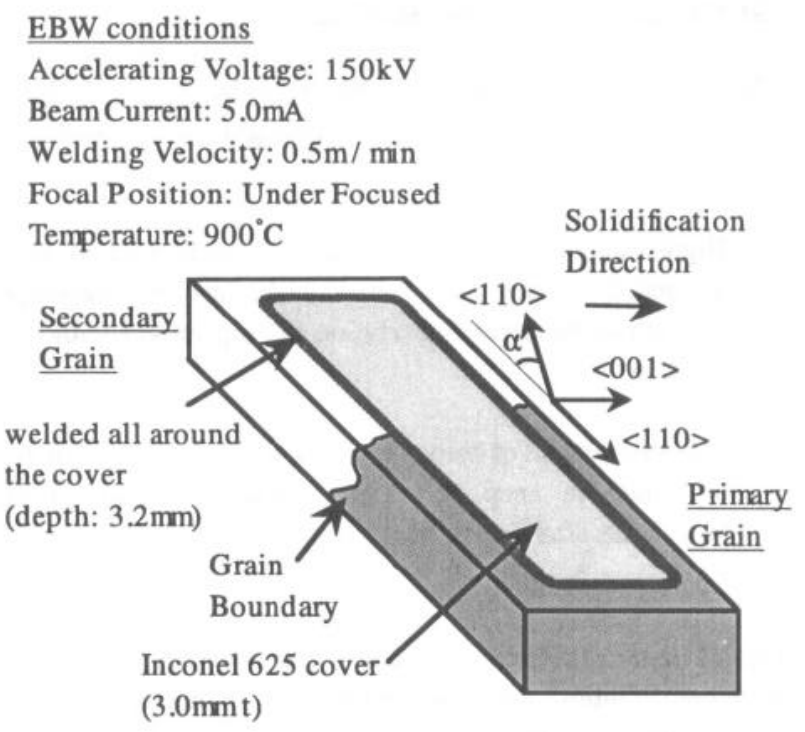

Figure 4: EBW direction was arranged perpendicular to the grain boundary whose misorientation angle was $\alpha$. 


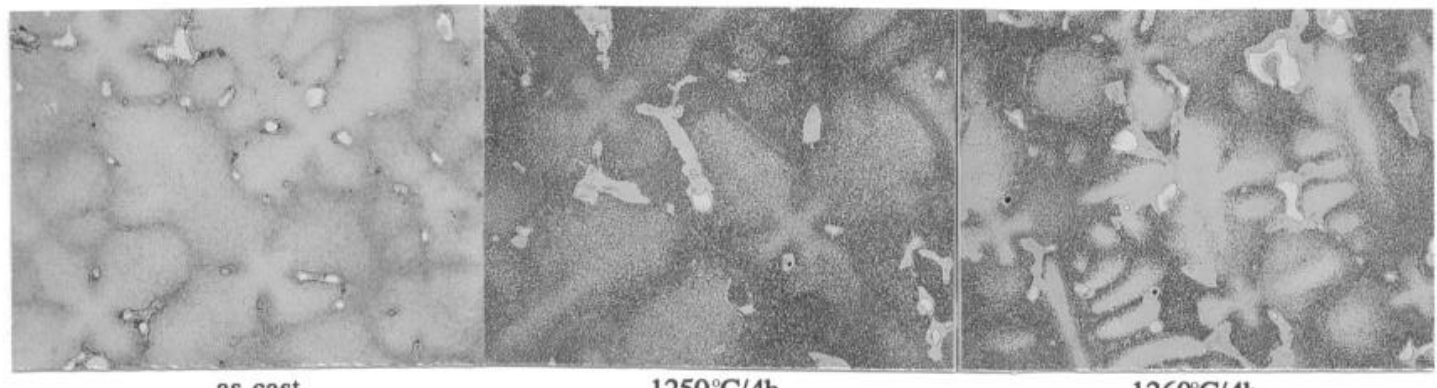

as-cast

$1250^{\circ} \mathrm{C} / 4 \mathrm{~h}$

$1260^{\circ} \mathrm{C} / 4 \mathrm{~h}$

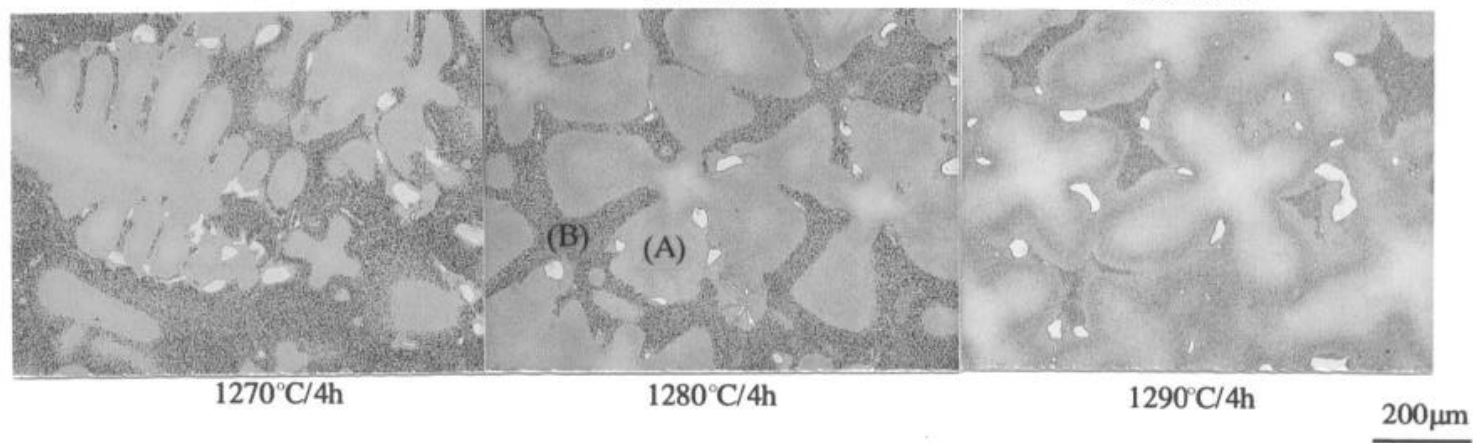

Figure 5: Typical microstructure of YH61 after various solution heat treatment and that of as-cast.

(A) indicates the region where $\gamma^{\prime}$ was completely solutioned and (B) is the region where $\gamma^{\prime}$

was not solutioned.

A specimen was machined from the above-mentioned slabs for evaluating electron beam (EB) weldability of SC with a grain boundary. Electron beam welding (EBW) was carried out after the solution heat treatment. A schematic of the sample and conditions of EBW are shown in Figure 4. Before (after the EBW) and after aging, existence of cracks was investigated by the liquid penetrant test method.

\section{Results and Discussion}

\section{The Effect of Solution Heat Treatment Conditions}

Although the design approach for the alloy chemistry of YH61 was detailed in another publication ${ }^{[5]}$, highlights of its chemistry is summarized below:

(1) Higher amounts of refractory elements such as Ta, W and Re are added in order to realize a similar level of creep-rupture strength as the second-generation SC superalloys without full solution

(2) A higher content of boron compared to conventional DS alloys was used to keep an adequate level of boron at grain boundaries after solution heat treatment.

Typical microstructures of YH61 after several solution heat treatment conditions are shown in Figure 5. The effect of solution heat treatment temperature on the volume percent of solutioned $\gamma^{\prime}$ is shown in Figure 6. In this figure, data for a final solution heat treatment time of $4 \mathrm{~h}$ are plotted. The term " volume percent of solutioned $\gamma^{\prime}$ " is used to describe the volume percent of the region in which $\gamma^{\prime}$ is completely solutioned at the solution heat treatment and precipitated as fine particles during aging.

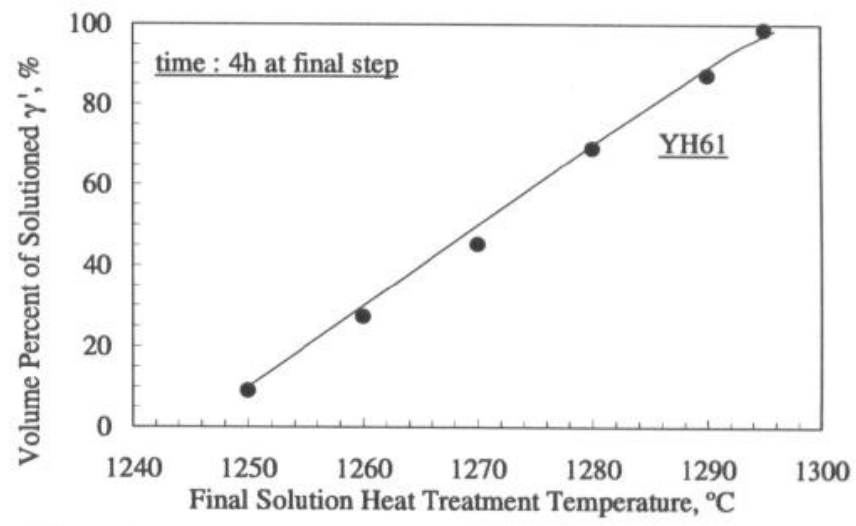

Figure 6: Volume percent of solutioned $\gamma^{\prime}$ increased linearly with increasing solution heat treatment temperature in this temperature range.

A Linear relationship between the volume percent of solutioned $\gamma^{\prime}$ and temperature was observed between 1250 and $1295^{\circ} \mathrm{C}$. Although almost $100 \%$ solutioning with no incipient melting can be achieved in this alloy, residual eutectic $\gamma \gamma^{\prime}$ colonies cannot be dissolved without incipient melting due to the higher content of boron in this alloy.

Figure 7 describes the relationship between the solution heat treatment time and the volume percent of solutioned $\gamma^{\prime}$ at $1280^{\circ} \mathrm{C}$. At this temperature, the volume percent of solutioned $\gamma^{\prime}$ increased with time and was saturated at about $70 \%$. 


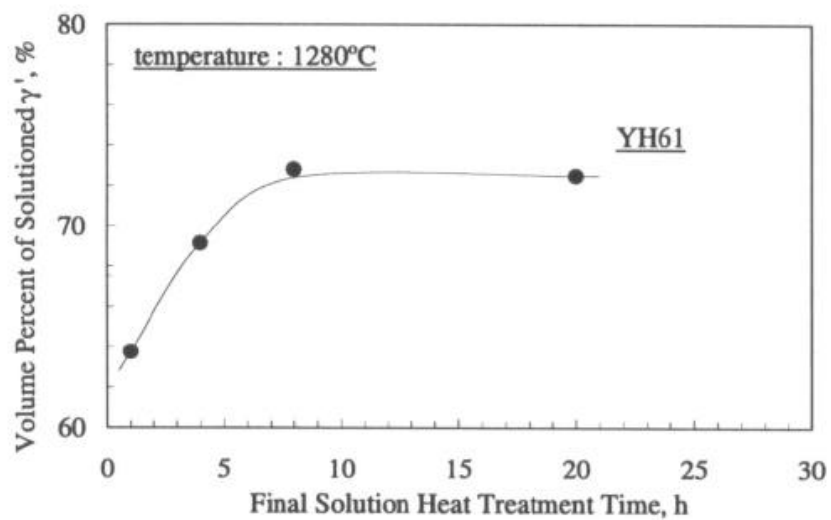

Figure 7: Volume percent of solutioned $\gamma^{\prime}$ was saturated to about $70 \%$ with increasing solution heat treatment time at $1280^{\circ} \mathrm{C}$.

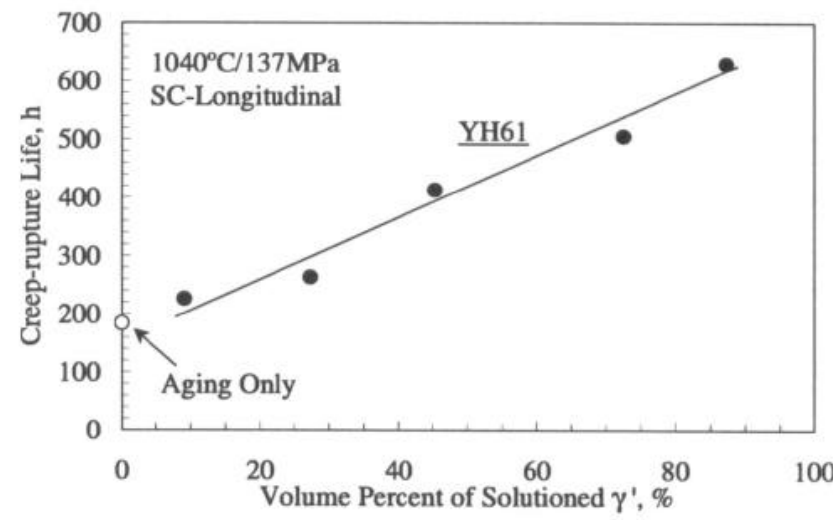

Figure 8: Creep-rupture life of SC longitudinal direction increased with increasing volume percent of solutioned $\gamma^{\prime}$.

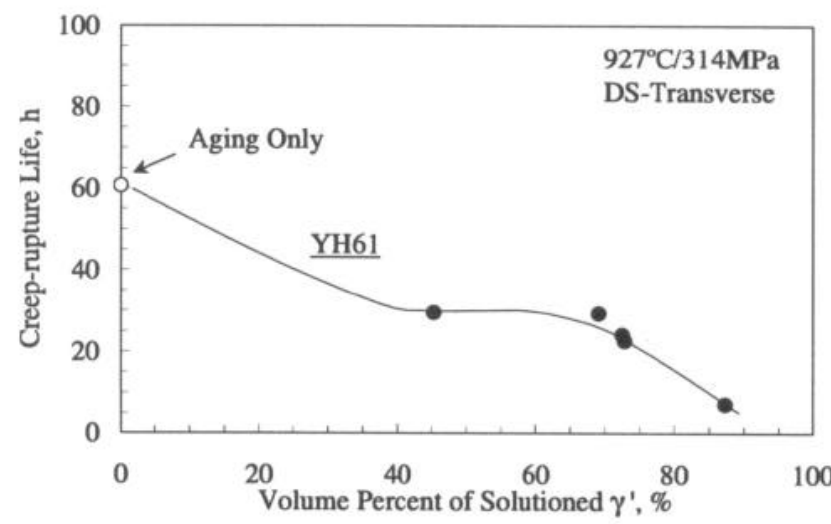

Figure 9: Creep-rupture life of DS transverse direction decreased with increasing volume percent of $\gamma^{\prime}$. DS transverse direction should be considered as substitution for HAB.

The effects of solution heat treatment on the creep-rupture life of defect-free SC longitudinal direction and DS transverse direction are shown in Figures 8 and 9, respectively. The creep-rupture life in the DS transverse direction was evaluated for simulating the creep-rupture life of SC with HAB. The creep-rupture life of the defect-free SC longitudinal direction was improved by increasing the volume percent of solutioned $\gamma^{\prime}$. Although this result has already been established, it must be noted that the creep-rupture life in the DS transverse direction decreased with increasing the volume percent of solutioned $\gamma^{\prime}$. It was pointed out in our previous study [5] that the grain boundary surrounded by the non-solutioned $\gamma^{\text {' }}$ (Figure 10-a) still contains higher levels of boron after solution heat treatment. On the other hand, the grain boundary exposed to the solutioned $\gamma^{\prime}$ (Figure 10-b) was found to contain lower amounts of boron after solution heat treatment. If the solution heat treatment temperature or the treatment time is increased, the increase in the volume percent of solutioned $\gamma^{\prime}$ also increases the percentage of the exposed grain boundary. Thus, these could be considered as reasons why creep-rupture life in the DS transverse direction decreased with increasing the volume percent of solutioned $\gamma^{\prime}$.

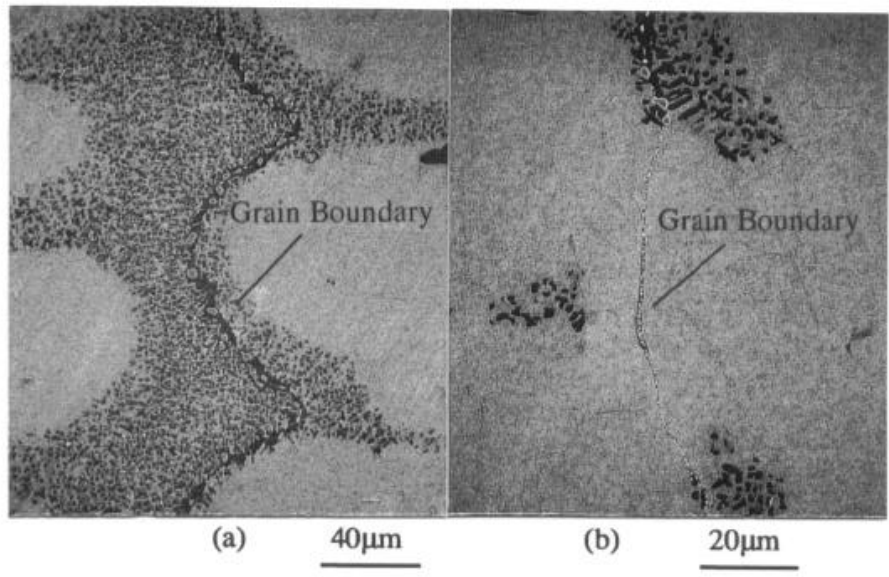

Figure 10: Two typical grain boundary structures after solution heat treatment (Final step: $1290^{\circ} \mathrm{C} / 4 \mathrm{~h}$ ).

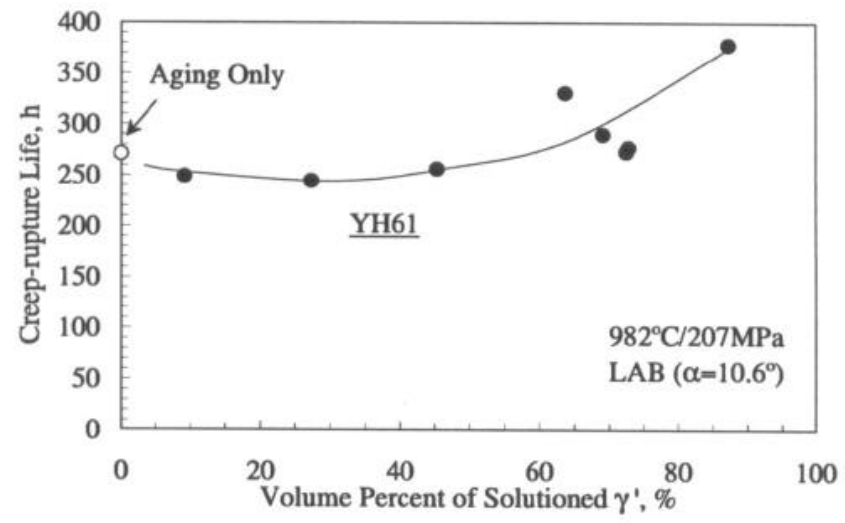

Figure 11: Decrease in creep-rupture life with increasing volume percent of solutioned $\gamma^{\prime}$ was not observed for LAB.

In the case of LAB $\left(\alpha=10.6^{\circ}\right)$, no significant degradation of SC transverse creep-rupture life was observed with increasing the volume percent (Figure 11). Additionally, a moderate LAB creep-rupture life was retained up to about $6^{\circ}$ in SC610 which was full solutioned and did not contain boron (Figure 18). It can be deduced from these results that the presence of boron at grain boundaries does not play an important role in LAB while boron is essential for HAB strength. Therefore, it follows that the solution heat treatment condition would not influence the LAB strength 
significantly since diffusion of boron from the grain boundary during solution heat treatment is not a major issue for LAB strength. However, it must be noted that the addition of boron increases the misorientation angle at which there is a fall-off of strength, or rather, the addition of boron extends the range of LAB.

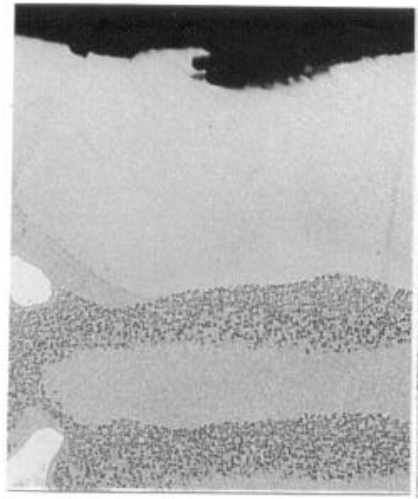

$1275^{\circ} \mathrm{C} / 4 \mathrm{~h}$ $100 \mu \mathrm{m}$

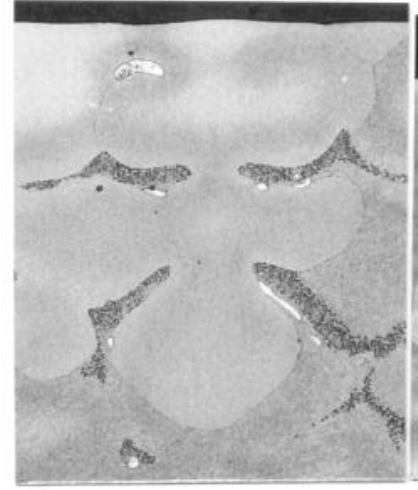

$1290^{\circ} \mathrm{C} / 4 \mathrm{~h} \quad \underline{200 \mu \mathrm{m}}$

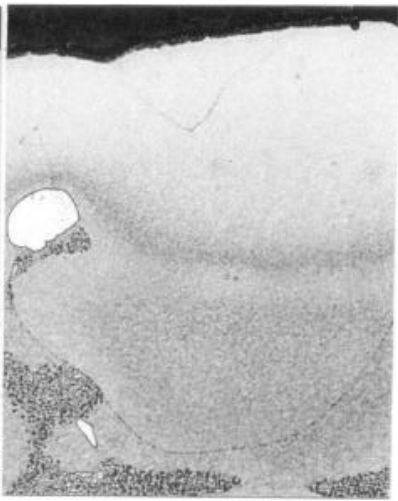

$1283^{\circ} \mathrm{C} / 4 \mathrm{~h}$

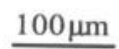

Figure 12: Depth of the recrystallization as a function of solution heat treatment temperature in SC610

Figure 12 shows typical micrographs of recrystallized grains in SC610. In order to apply this result to YH61, Figure 13 describes the maximum depth of recrystallization as a function of the volume percent of solutioned $\gamma^{\prime}$. It is reasonable to suppose that the relationship between the volume percent and the depth can apply in principle to YH61 as well as other SC superalloys, because growth of recrystallization was observed to depend on the existence of a non-solutioned $\gamma^{\prime}$ barrier but to be independent of the solution heat treatment temperature as long as non-solutioned $\gamma^{\prime}$ existed. At temperatures below the solidus, recrystallization only occurred in $\gamma^{\prime}$-denuded layer which was caused by the formation of a surface oxide layer. Although the recrystallized grain grew into the $\gamma^{\prime}$ solutioned area at temperatures above the solidus, non-solutioned $\gamma^{\prime}$ still hindered the growth. The recrystallized grain could not grow thermodynamically until full-solutioning was completed. These observations suggested that severe recrystallization cannot occur as long as non-solutioned $\gamma^{\prime}$ exists. Walston et al. ${ }^{[12]}$ proposed another effective prevention method for similar crystal growth by borides or carbides. However, a continuous network of the non-solutioned $\gamma^{\prime}$, which can be formed in a higher volume percent than borides or carbides, would be necessary for preventing the severe recrystallization observed in IGT castings since their large and complicated features introduces higher casting residual stress than aero-engine turbines. It follows that a partial solution heat treatment should be adopted for IGT castings while the alloy's potential for strength can not be fully exhibited in this condition.

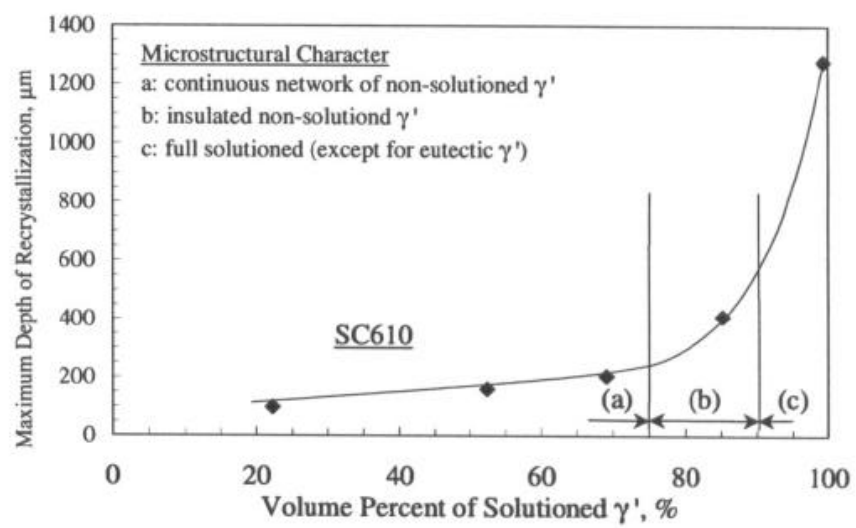

Figure 13: The effect of volume percent of solutioned $\gamma^{\prime}$ on growth of recrystallized grains.

These results have led to the conclusion that determining the solution heat treatment condition is one of the most important procedures for manufacturing reliable IGT buckets and vanes with low cost. Conditions to control the volume percent of solutioned $\gamma^{\prime}$ should be determined by taking account of the followings:

(1) Defect-free SC strength

(2) LAB strength

(3) HAB strength (in case of allowing HAB)

(4) Preventing severe recrystallization

It must be noted that the condition for a defect-free SC strength conflicts with that required for $\mathrm{HAB}$ strength and preventing severe recrystallization. A compromise condition should be selected in order to meet the design criterion for each part. Finally, it must be noticed that an extreme insufficiency of solutioning causes lower hot corrosion resistance and phase stability, which is not discussed in this paper.

\section{The Effect of Grain Boundary misorientation angle}

The relationship between grain boundary misorientation angle $(\alpha)$ and LAB or HAB strength is one of the major concerns for IGT manufacturers. From the viewpoint of alloy metallurgy, the effect of $\alpha$ on deformation behavior is also interesting.

Tensile property. Figure 14 shows the relationship between $\alpha$ and $0.2 \%$ yield strength at $700^{\circ} \mathrm{C}$. No significant fall-off of the $0.2 \%$ yield strength was observed. Dependency of $0.2 \%$ yield strength on $\alpha$ at room temperature exhibited a tendency similar to that shown in this figure. Although the increase in $\alpha$ caused only 
a slight decrease in the $0.2 \%$ yield strength, fracture can be divided into three types depending on their $\alpha$ values (Figure 15). Specimens, whose $\alpha$ was less than about $4^{\circ}$, deformed uniformly and finally fractured at the center of gauge length (Type A). For $\alpha$ values between about 4 and $10^{\circ}$, significant deformation occurred in the rotated grain whereas apparent deformation was not observed in the primary grain (Type B). In this case, sheared fracture occurred in the rotated grain. In specimens whose $\alpha$ was more than about $10^{\circ}$, brittle fracture at the grain boundary was observed (Type C). Although unilateral deformation was also observed in the rotated grain, it did not lead to fracture.

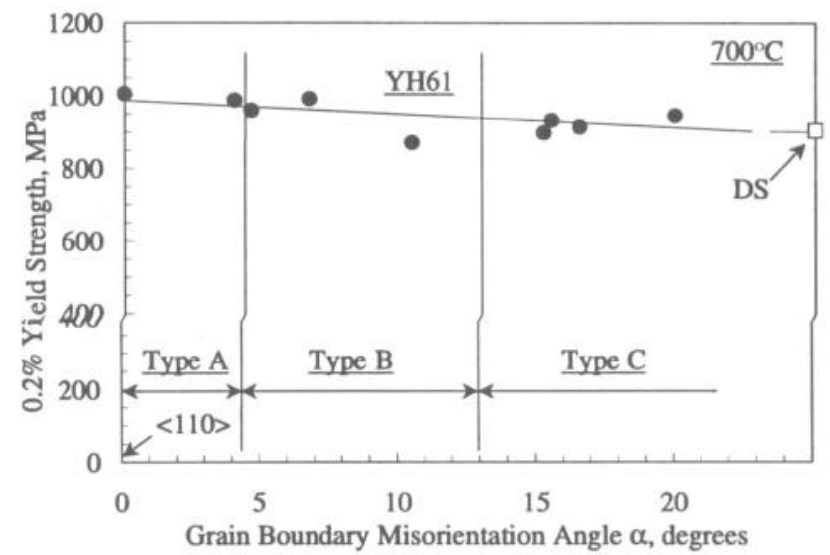

Figure 14: Relationship between grain boundary misorientation angle and $0.2 \%$ yield strength.

Type A

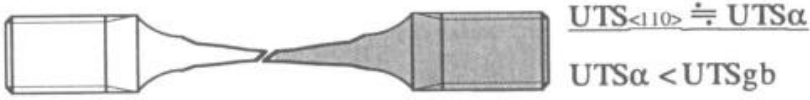

Type B

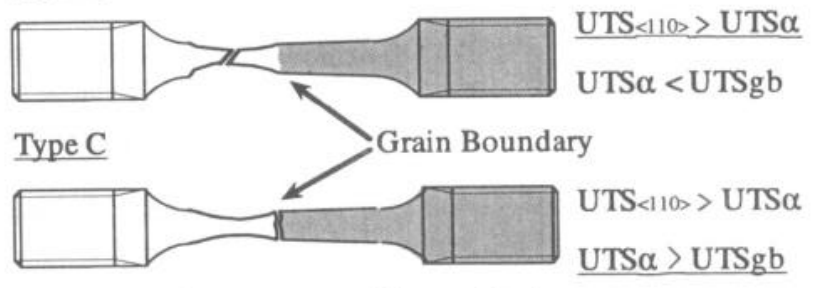

Secondary Grain

Primary Grain

Figure 15: Schematic illustration of deformation and fracture types for YH61 with $\mathrm{LAB}$ or $\mathrm{HAB}$.

These obsevations can be explained by the orientation dependence of $0.2 \%$ yield strength. Shah and Duhl ${ }^{[13]}$ pointed out that orientations along the $\langle 001\rangle$ to $\langle 110\rangle$ boundary of the standard stereographic triangle deform by octahedral slip, but do not obey the Schmid's law since $\langle 001\rangle$ and $\langle 110\rangle$, whose Schmid factors are equivalent, exhibit different yield strengths. Figure 16 shows the relationship between $\alpha$ and the $0.2 \%$ yield strength of defect-free SC YH61 as well as the data of Shah and Duhl. These data correspond to the $0.2 \%$ yield strength for the secondary grain itself. The difference of the $0.2 \%$ yield strength between $<001>$ and $<110>$ was also observed in YH61. Although it is not clear whether the orientation dependence of the yield strength obeys the Schmid's law, it must be noted that the yield strength decreases with increasing $\alpha$ for $\alpha$ values less than about $20^{\circ}$. Thus, the yield strength of the secondary grain decreases with increasing $\alpha$ while that of the primary grain is not affected by $\alpha$.

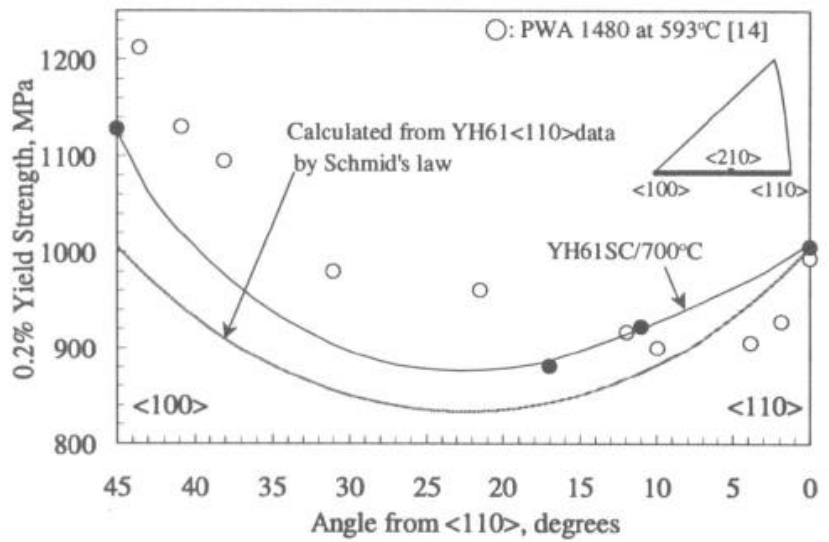

Figure 16: For angles less than about $20^{\circ}, 0.2 \%$ yield strength decreases with increasing the angle. This range corresponds to the rotation angle of the secondary grain.

It seems reasonable to suppose from these results that the different behavior observed for the three deformation types can be explained by comparing ultimate tensile strength value of the primary grain (UTS $<110>$ ), the rotated grain (UTS $\alpha$ ) and the grain boundary (UTS $\mathrm{gb}_{\mathrm{b}}$ ). For type $\mathrm{A}$, it can be considered that deformation behavior is the same as defect-free SC. In this range, it must be noted that shear occurred across the grain boundary. Therefore the existence of a grain boundary is thought to be insignificant for these $\alpha$ values, whereas a grain boundary can be considered as an obstacle for shear at greater $\alpha$ values as discussed later. For type B, deformation was localized in the rotated grain since UTS $\alpha$ becomes lower than UTS $<110>$ with increasing $\alpha$. Considering that the specimen was not fractured at the grain boundary, type B deformation can be included in a SC deformation. Classified with regard to the deformation behavior alone, "LAB" may correspond to $\alpha$ values for type A and B. For type C, although UTS $\alpha$ still decreases with increasing $\alpha$, it can be supposed that UTSgb fell rapidly and therefore it became lower than UTS $\alpha$. Thus, the specimen fractured at the grain boundary. In this range, even if the yield strength for higher $\alpha$ values retained more than about $90 \%$ of the yield strength for $\langle 110\rangle$, the deformation can no longer be regarded as a SC deformation. This $\alpha$ may correspond to "HAB". It follows from these results that the argument, whether life across $\mathrm{LAB}$ or $\mathrm{HAB}$ is comparable to that of a defect-free $\mathrm{SC}$, is not valid unless their crystallographic orientations are clearly specified. It is considered that both the grain boundary strength and strength anisotropy of the rotated grain should be taken into account for evaluating the life of the SC with LAB or HAB. 
Creep-rupture property. Figures 17 and 18 show the relationship between $\alpha$ and creep-rupture life for different test temperatures. Although a significant fall-off of the $0.2 \%$ yield strength for $\alpha$ was not observed, creep-rupture life exhibited apparent fall-off at higher $\alpha$ values. Furthermore, the magnitude of the fall-off increased with increasing temperature. For $760^{\circ} \mathrm{C} / 490 \mathrm{MPa}$, the creep-rupture life of the specimen whose $\alpha$ was $15.5^{\circ}$ retained more than $70 \%$ of $\mathrm{SC}_{<110>}$ life. On the other hand, the creep-rupture life of this specimen decreased to $30 \%$ of $\mathrm{SC}_{<110>}$ life at $982^{\circ} \mathrm{C} / 207 \mathrm{MPa}$.

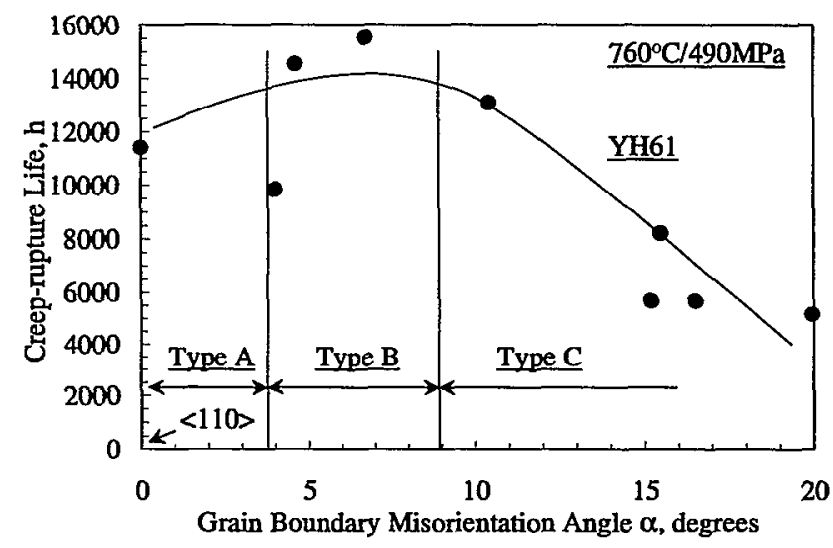

Figure 17: The effect of grain boundary misorientation angle on creep-rupture life for $760^{\circ} \mathrm{C} / 490 \mathrm{MPa}$.

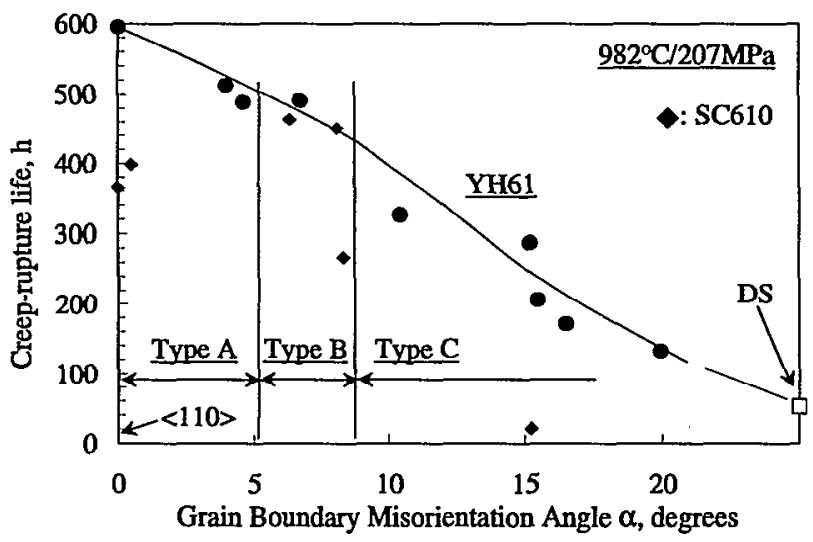

Figure 18: The effect of grain boundary misorientation angle on creep-rupture life for $982^{\circ} \mathrm{C} / 207 \mathrm{MPa}$.

It is found that the transition angle of which deformation type changes for $\mathrm{A}$ to $\mathrm{B}$ and $\mathrm{B}$ to $\mathrm{C}$ do not depend on temperature or stress. The transition angle for the change from type $A$ to $B$ is about $4^{\circ}$ for each creep-rupture and for each tensile test condition. The same tendency was observed for the transition angle for the change from type $B$ to $C$ at about $10^{\circ}$. It follows from these results that classification with respect to the deformation type will help understanding the LAB or HAB tolerability of an alloy since the transition angle hardly depends on the test conditions whereas the magnitude of the fall-off strongly depends on the conditions.
Although the fall-off of creep-rupture life across $L A B$ or $H A B$ was observed for YH61, the absolute value was comparable to the transverse creep-rupture life of a second-generation DS superalloy ${ }^{[6]}$ even for $\alpha$ of about $15^{\circ}$. This result leads to the conclusion that an optimized solution heat treatment condition and the presence of grain boundary strengthening elements in YH61 make it possible to realize a good balance between its $\mathrm{LAB}$ or HAB strength and defect-free SC strength.

Low cycle fatigue (LCF) property. A strain-controlled LCF test provided another interesting result for LAB or HAB strength. Deformation was localized in the rotated grain, which was the weaker grain, for the tensile test or the creep-rupture test, while every specimen fractured at the grain boundary during the LCF test. Although the life of the $10^{\circ}$-misoriented specimen was comparable to that of the $\mathrm{SC}_{<110 s}$ specimen in the LCF test, a rapid fall-off of the life was observed when $\alpha$ increased above about $12^{\circ}$ (Figure 19).

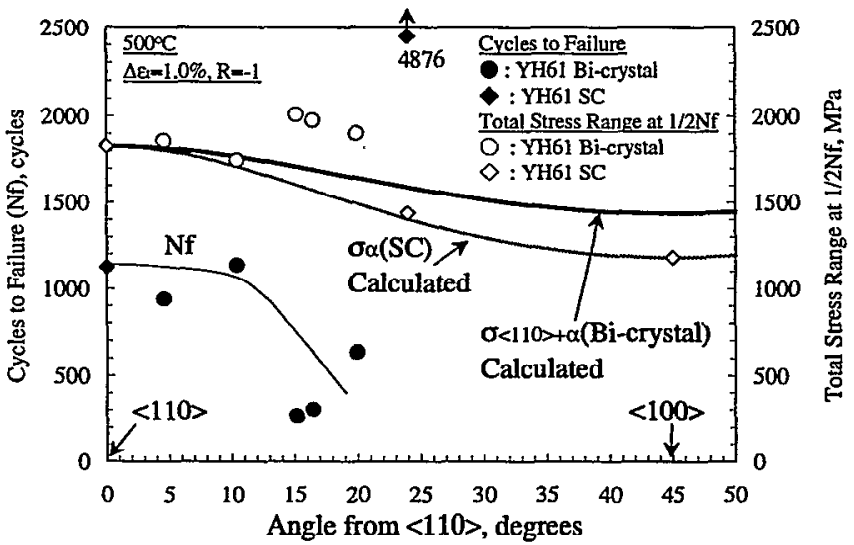

Figure 19: The effect of $\alpha$ on LCF life for bi-crystal( $\bullet$ ) and single crystal $(*)$. For the bi-crystal, the angle from $\langle 110\rangle$ corresponds to the grain boundary misorientation angle $\alpha$. Observed total stress ranges at $1 / 2 \mathrm{Nf}$ for each specimen are also plotted $(0, \diamond)$. The lines $\sigma_{<110>+\alpha}$ and $\sigma \alpha$ describe the theoretical total stress for the bi-crystal and single crystal, respectively. These values are calculated from measured elastic moduli.

In order to understand this particular deformation mechanism for the strain-controlled LCF test, experimental results for a total stress range at $1 / 2 \mathrm{Nf}$ are compared with theoretical values (Figure 19). Although the total stress range is the sum of the elastic and plastic stress ranges, only the elastic stress is taken into account because no plastic stress was observed at $1 / 2 \mathrm{Nf}$. Strain for the primary grain $\left(\varepsilon_{1}\right)$, the secondary grain $\left(\varepsilon_{2}\right)$ and total strain of the bi-crystal (घ) have following relationship,

$$
\varepsilon_{1}=1 / 2 \cdot\left(\varepsilon_{1}+\varepsilon_{2}\right),
$$

and total stress for the bi-crystal $\left(\sigma_{<110>+a}\right)$ can be written as

$$
\sigma_{<110>+\alpha-\varepsilon_{1}} E_{1}-\varepsilon_{2} E_{2}=2 \cdot E_{1} \cdot E_{2} /\left(E_{1}+E_{2}\right) \cdot \varepsilon_{1}
$$


where $E_{1}$ is the Young's modulus for the primary grain and $E_{2}$ for the secondary grain. $E_{1}$ is equivalent to $E_{<110}$, and $E_{2}$ can be described as $E_{\alpha}$ while $\varepsilon_{t}$ is equal to 0.01 in this study. Therefore,

$$
\sigma_{<110>+\alpha}=2 \cdot E_{<110} \cdot E_{\alpha} /\left(E_{<110>}+E_{\alpha}\right) \cdot 0.01
$$

where $\mathrm{E}_{\text {<urws }}$ is the Young's modulus for <uvw> direction. The Young's modulus of a cube single crystal for any direction can be written as $[14][15]$

$$
\begin{aligned}
E(\theta, \phi)= & {\left[s_{11}-2\left(s_{11}-s_{12}-1 / 2 \cdot s_{44}\right)\right.} \\
& \left.\times \sin 2 \theta\left(\cos 2 \theta+1 / 4 \sin ^{2} \theta \cdot \sin ^{2} 2 \phi\right)\right]^{-1},
\end{aligned}
$$

where $s_{11}, s_{12}$ and $s_{44}$ are elastic compliance, $\theta$ the rotation angle from [001] axis and $\phi$ the angle between the projection on (100) plane and [100] axis ${ }^{[15]}$. Since the stress axis is only rotated on the (100) plane in this study, $\theta$ is equal to 0 and $\phi$ can be taken as $(45-\alpha)$ by using rotation angle from [110] axis. Then, equation (4) can be written in terms of $\alpha$ (degrees) as

$$
E(\alpha)=\left[s_{11}+\sin ^{2}(45-\alpha) \cdot \cos ^{2}(45-\alpha) \cdot\left(2 \cdot s_{12}+s_{44}-2 \cdot s_{11}\right)\right]^{-1}
$$

Moreover, for these stress axes, the above elastic compliances can be described as

$$
s_{11}=1 / E_{<100>}, s_{44}=1 / G_{<100>}, s_{12}=2 / E_{<110>}-s_{11}-1 / 2 \cdot s_{44},
$$

where $\mathbf{G}_{<100>}$ is the shear modulus for $<100>$ direction. For YH61, experiments showed that $E_{<100\rangle}=118 \mathrm{GPa}, E_{<110\rangle}=183 \mathrm{Gpa}$ and $\mathrm{G}_{<100\rangle}=102 \mathrm{GPa}$ are valid at $500^{\circ} \mathrm{C}$. Also, the relationship between the total stress range for the bi-crystal and $\alpha$ can be calculated from equations (3) and (5) (Figure 19). The total stress range for SC rotated by $\alpha$ from $\langle 110\rangle\left(\sigma_{\alpha}\right)$ is also plotted in Figure 19. It is obtained from the equation;

$$
\sigma_{\alpha}=E_{\alpha} \cdot \varepsilon_{\mathrm{t}}
$$

In Figure 19, a significant fall-off of the life was observed for the bi-crystal whose $\alpha$ was higher than about $12^{\circ}$ as mentioned above. It is remarkable that the bi-crystal which suffered from the lower life showed a higher experimental total stress than the calculated value while the stress range should decrease with increasing $\alpha$ because of the decrease in the Young's modulus as calculated in equation (3). For $\alpha$ values below about $12^{n}$ and for a whole range of SC, the experimental value followed the calculated value. In a $S C$ rotated $24^{\circ}$ from $\langle 110\rangle$, a lower total stress increased the life about four times that of $\mathrm{SC}_{<110>}$ and the bi-crystal showed a comparable life to the $\mathrm{SC}_{<110\rangle}$ within the range where the experimental value followed the calculated value.

From these observations, the following conclusions are considered as applicable. When $\alpha$ is less than about $12^{\circ}$, deformation of the bi-crystal took place in accordance with equation (1) because no significant deviation of the experimental stress range from the calculated value was observed. For these values of $\alpha$, the bi-crystal retains the life of $\mathrm{SC}_{<110>}$ or shows a slightly higher life because the total stress decreases with increasing $\alpha$. Therefore, deformation of the bi-crystal can be considered as being the same as $\mathrm{SC}$ in this range. When $\alpha$ is higher than about $12^{\circ}$, higher stresses must have significantly decreased the life. It is thought that the existence of the grain boundary causes the difference between the experimental and the calculated stress ranges. The grain boundary, which lies perpendicular to the stress axis, can be regarded as an obstacle to shear deformation across the grain boundary. Since the stress increased to the determined strain range in the strain-controlled test, the resultant high stress must have been used to elongate the grain boundary. Since the grain boundary of high strength superalloys suffers from poor ductility ${ }^{[16]}$, the additional stress, which was not observed for lower $\alpha$, must have caused the significant shortening of life at higher $\alpha$ values. It should be noted that thermal stresses, which are more important to advanced IGT than centrifugal stress, is a strain-controlled stress. It is concluded from this discussion that close attention must be paid to $L A B$ or HAB at the parts or the sections where thermal stress can be of a major concern. It is also thought that the strain-controlled test is most essential test method to evaluate $\mathrm{LAB}$ or $\mathrm{HAB}$ strength of a $\mathrm{SC}$ superalloy.

Electron beam weldability. In order to allow the existence of LAB or HAB in IGT castings, the effects of $\alpha$ on weldability as well as mechanical properties of SC superalloys should be investigated.

Grain boundary cracks caused by EB welding were not observed when $\alpha$ was lower than about $10^{\circ}$. For $\alpha$ above this value, both cracked and non-cracked grain boundaries were observed. Although the presence of grain boundary cracks was investigated after a post weld heat treatment in this study, almost all of the cracks had been observed after welding. Welding defects other than grain boundary cracking were not observed.

When a weldment cools to ambient temperature, tensile stress is generated near the weldment. Typically, the magnitude of this stress may be as high as the yield stress of the parent material ${ }^{[17]}$. Therefore, the grain boundary may elongate under this stress if the welding is performed across the LAB or HAB. Since the stress can be considered as a kind of thermal stress, it is possible that the grain boundary cracking can be prevented if $\mathrm{LAB}$ or $\mathrm{HAB}$ have enough ductility to elongate to strain values which are balanced by the thermally induced strain. The higher LAB resistance observed for YH61 is considered to be necessary for IGT castings from the viewpoint of weldability as wcll as mechanical properties.

\section{Summary}

Two important issues for the adaptation of SC castings to IGT were studied for YH61.

\section{The effect of solution heat treatment condition}

(1) Increasing the solutioned area decreased the $\mathrm{HAB}$ strength and increased the depth of recrystallization.

(2) A compromise solution heat treatment condition was selected 
for the SC with some degree of grain defects since the best solution heat treatment condition for defect-free SC strength conflicts with that required for HAB strength and that for necessary to preventing severe recrystallization.

The effect of grain boundary misorientation angle $(\alpha)$

(3) The effect of $\alpha$ on $0.2 \%$ yield strength, creep-rupture life and low cycle fatigue strength were studied. The magnitude of the fall-off as a function of $\alpha$ increased with increasing test temperatures for tensile and creep tests.

(4) In the bi-crystal test, an increase in $\alpha$ caused a decrease in yield strength of the rotated grain as well as the grain boundary strength. Based on crystal orientations, the strength of the rotated grain may be lower than that of resultant grain boundary. Therefore, both the grain boundary strength and strength anisotropy of the rotated grain should be taken into account when evaluating the life of SC with LAB or HAB.

(5) Different deformation behaviors were observed for loadcontrolled tests such as the creep test and strain-controlled tests such as the LCF test. The fall-off of life for higher $\alpha$ values was remarkable for the strain-controlled test due to its specific deformation mechanism.

Although the fall-off of life as a function of $\alpha$ was observed in YH61, the absolute life of higher $\alpha$ values was still comparable to that of conventional DS superalloy's transverse direction. An optimized solution heat treatment condition and grain boundary strengthening elements provide a higher level of compatibility for both defect-free SC strength and HAB strength. Since effects of $\alpha$ on alloy mechanical properties are influenced by temperature, stress level and strain-mode, a practical $\alpha$-tolerance should be determined for each component or each section after considering their operation conditions.

\section{Acknowledgments}

The authors would like to thank Dr. B. Önay, Hitachi Research Lab., Hitachi, Ltd., for his reviewing the manuscript. The authors gratefully acknowledge helpful discussions with Dr. N. Matsuda, Hitachi Engineering Co., on the fatigue properties of YH61. The authors acknowledge the many metallurgical tests for YH61 which were performed at Hitachi Research Lab. by M. Kobayashi, N. Watanabe, T. Kashimura and K. Sato.

\section{References}

1. D. Goldschmidt, "Single-Crystal Blades", Materials for Advanced Power Engineering 1994, Part I, ed. D. Coutsouradis et al., (Netherlands: Kluwer Academic publishers, 1994), 661-674.

2. M. Cybulsky and P.E.C. Bryant, "Application of Aero-Engine Turbine Materials Technology to Industrial Gas Turbines", Advanced Materials and Coatings for Combustion Turbines, ed. V.P. Swaminathan and N.S. Cheruvu, (ASM, 1993), 23-27.

3. Thomas Barker, "Siemens' New Generation", Turbomachinery
International, 1995, Jan/Feb: 20-22.

4. Hans-Jürgen Kiesow and Dilip Mukherjee, "The GT24/GT26 Family Gas Turbine: Design for Manufacturing", Advances in Turbine Materials, Design and Manufacturing, ed. A. Strang et al., (London, UK: The Institute of Materials, 1997), 159-172.

5. H. Tamaki et al., "Development of A New Ni-Based Single Crystal Superalloy for Large Sized Buckets", Materials for Advanced Power Engineering 1998, Part II, ed. J. Lecomte-Beckers et al., (Germany: Forschungszentrum Jülich GmbH, 1998), 1099-1110.

6. M. Sato, H. Tamaki et al., "High Temperature Strength of Large Size SC and DS Buckets for Industrial Gas Turbines", ASME Paper 95-GT-365, (ASME, 1995).

7. J.J. Jackson et al., 'The Effect of Volume Percent of Fine $\boldsymbol{\gamma}^{\text {' on }}$ Creep in DS Mar-M200 + Hf ", Metall. Trans. A, 8A (1977), 1615-1620.

8. Earl W. Ross and Kevin S. O'Hara, 'René N4: A First Generation Single Crystal Turbine Airfoil Alloy with Improved Oxidation Resistance, Low Angle Boundary Strength and Superior Long Time Rupture Strength", Superalloys 1996, ed. R.D. Kissinger et al., (TMS, 1996), 19-25.

9. A.D. Cetel and D.N. Duhl, "Second Generation Columnar Grain Nickel-Based Superalloy", Superalloys 1992, ed. S.D. Antolovich et al., (TMS, 1992), 287-296.

10. Phil S. Burkholder et al, "CM186LC\& Alloy Single Crystal Turbine Vanes", ASME Paper 99-GT-379, (ASME, 1999).

11. K. Sato, H. Tamaki et al., U.S. Patent 5,916,382, 'High Corrosion Resistant High Strength Superalloy and Gas Turbine Utilizing The Alloy", 1999.

12. W.S. Walston et al., "A New Type of Microstructural Instability in Superalloys - SRZ", Superalloys 1996, ed. R.D. Kissinger et al., (TMS, 1996), 9-18.

13. D.M. Shah and D.N. Duhl, "The Effect of Orientation, Temperature and Gamma Prime Size on The Yield Strength of $A$ Single Crystal Nickel Base Superalloy", Superalloys 1984, ed. Maurice Gell et al., (TMS, 1984), 105-114.

14. J.F. Nye, "Physical Properties of Crystals", (London, UK: Oxford University Press, 1960).

15. Tadashi Hasebe et al., 'High Temperature Low Cycle Fatigue and Cyclic Constitutive Relation of MAR-M247 Directionally Solidified Superalloy", J. Eng. Mat. \& Tech., 114 (1992), 162-167.

16. B.J. Piearcey and B.E. Terkelsen, "The Effect of Unidirectional Solidification on the Properties of Cast Nickel-Base Superalloys", Trans. TMS-AIME, 239 (1967), 1143-1150.

17. J.M. Robinson et al., "Residual Stress and Distortion Associated with Electron Beam Welding of Waspaloy", Joining and Repair of Gas Turbine Components, ed. Donald Tillack and Raymond Thompson, (ASM, 1997), 101-107. 